\title{
Enantioselective Synthesis of Succinimides by Michael Addition of Aldehydes to Maleimides Organocatalyzed by Chiral Primary Amine-Guanidines
}

\author{
Angel Avila, ${ }^{[a]}$ Rafael Chinchilla, ${ }^{*[a]}$ Enrique Gómez-Bengoa, ${ }^{[b]}$ and Carmen Nájera ${ }^{*[a]}$
}

Keywords: Chiral guanidines / Organocatalysis / Michael addition / Maleimides / Succinimides

\begin{abstract}
The monoguanylation of $(1 S, 2 S)$ - and $(1 R, 2 R)$-cyclohexane-1,2diamine affords chiral primary amine-guanidines, which have been used as chiral organocatalysts for the enantioselective Michael addition of aldehydes, particularly $\alpha, \alpha$-disubstituted, to maleimides. The reaction is carried out in the presence of imidazole as additive in aqueous DMF as solvent and affords the corresponding enantioenriched succinimides in high or quantitative yields and with enantioselectivities up to $96 \%$ ee.
\end{abstract}

\section{Introduction}

Maleimides are an important class of substrates, which have been successfully used in different asymmetric organocatalytic transformations. ${ }^{[1]}$ Particularly, the organocatalytic functionalization of maleimides provides easy access to chiral-substituted succinimide derivatives, which are compounds of interest due to the occurrence of the succinimide moiety in natural products and some clinical drug candidates. ${ }^{[2]}$ In addition, succinimides can be transformed into other important compounds such as $\gamma$ lactams, ${ }^{[3]}$ which are significant in the treatment of epilepsy, ${ }^{[4]}$ $\mathrm{HIV},{ }^{[5]}$ neurodegenerative disease and depression. ${ }^{[6]}$

The enantioselective Michael addition of carbon nucleophiles to maleimides is probably the most direct way of preparing enantioenriched succinimides following an organocatalytic approach. ${ }^{[1]}$ This has been frequently achieved using pro-nucleophiles containing highly acidic $\mathrm{C} \alpha$-hydrogens, by employing as organocatalysts chiral bifunctional compounds bearing both an acidic moiety and a tertiary amine. ${ }^{[1]}$ Thus, enantioinduction is achieved after formation of transition states involving close coordination of the maleimide and the enolate generated after deprotonation by the basic tertiary amine. However, pro-nucleophiles bearing $\mathrm{C} \alpha$-hydrogens that cannot be deprotonated by tertiary amines, such as aldehydes, require formation of the carbon nucleophile by other catalytic systems. Thus, the first enantioselective conjugate addition of aliphatic aldehydes to $N$-aryl-maleimides used $\alpha, \alpha$-phenylprolinol silyl ether as organocatalyst. ${ }^{[7]}$ The corresponding succinimides were obtained with very high enantioselectivity through a proposed transition state involving the formation of an enamine after reaction of the secondary amine with the aldehyde. However, the use of $\alpha, \alpha$-disubstituted aldehydes as pro-nucleophiles resulted in much lower enantioselectivities.

[a] Departamento de Química Orgánica, Facultad de Ciencias, and Instituto de Síntesis Orgánica (ISO), Universidad de Alicante, Apdo. 99, 03080 Alicante, Spain

Fax: +34965903549

E-mail: chinchilla@ua.es, cnajera@ua.es

[b] Departamento de Química Orgánica I, Universidad del País Vasco, Apdo. 1072, 20080 San Sebastián, Spain

- Supporting information for this article is available on the WWW under http://www.eurjoc.org/ or from the author.
Theoretical calculations (DFT and M06-2X) suggest a different $\mathrm{H}$-bond coordination pattern of the maleimide $(\mathrm{C}=\mathrm{O})$ and the catalyst (NH groups) as responsible for the enantioinduction switch observed when the reaction is carried out using these primary amine-guanidines or the previously reported primary amine-thioureas as organocatalysts.

Therefore, other organocatalysts suitable to be also employed with the "difficult" $\alpha, \alpha$-disubstituted aldehydes, leading to enantioenriched succinimides bearing contiguous quaternary-tertiary carbons, were subsequently developed. ${ }^{[1]}$ The most common and successful have been those incorporating both primary amine and thiourea moieties, ${ }^{[8]}$ such as the trifluoromethylated primary amine thioureas $1 \mathbf{1}^{[8 \mathrm{a}, \mathrm{b}]} \mathbf{2}^{[\mathrm{8a}, \mathrm{b}]}$ and $\mathbf{3},{ }^{[8 \mathrm{e}]}$ as well as the beyerane-containing thiourea $\mathbf{4},{ }^{[8 \mathrm{f}]}$ although noncovalent bifunctional organocatalysts based on the use of the primary amine of amino acids, combined to acid additives, have also been successfully used. ${ }^{[9]}$<smiles>FC(F)(F)c1cc(NC(=S)NC(c2ccccc2)c2ccccc2)cc(C(F)(F)F)c1</smiles><smiles>N[C@@H]1CCCC[C@H]1NC(=S)Nc1cc(C(F)(F)F)cc(C(F)(F)F)c1</smiles><smiles>NC[C@H](Cc1ccccc1)NC(=S)Nc1cc(C(F)(F)F)cc(C(F)(F)F)c1</smiles>

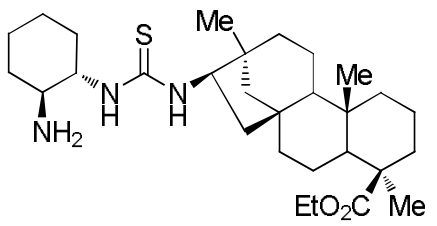

The use of chiral guanidines as organocatalysts has experienced a strong development in the last years, taking advantage of their strong basic character and coordinating capabilities. ${ }^{[10]}$ However, concerning their application as organocatalysts in enantioselective Michael addition of carbon nucleophiles to maleimides, their use has been rather limited. Only enantioselective processes involving deprotonation of some pro-nucleophiles bearing highly acidic $\mathrm{C} \alpha$-hydrogens have been reported, ${ }^{[10]}$ the use of aldehydes remaining unexplored.

Recently, we have communicated the use of new chiral primary amine-guanidines as organocatalysts for the enantioselective addition of $\alpha, \alpha$-disubstituted aldehydes to maleimides with opposite enantioselection than when using related thioureas. ${ }^{[11]}$ Herein, we present a full account of the use of these new amine-guanidines as chiral organocatalysts in the asymmetric Michael addition of aldehydes to maleimides leading to enantioenriched succinimides, improving their enantioselectivity and exploring the origin of the enantioinduction by theoretical calculations. 


\section{Results and Discussion}

The primary amine-guanidines $\mathbf{5 a}$ and $\mathbf{5 b}$ employed in this study were prepared directly in $50 \%$ yield by monoguanylation of $(1 S, 2 S)$-cyclohexane-1,2-diamine (5 eq) with diisopropylcarbodiimide and dicyclohexylcarbodiimide, respectively, in THF at room temperature for $48 \mathrm{~h}$ (Scheme 1).

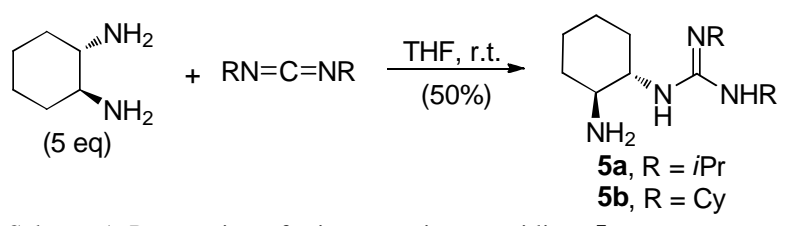

Scheme 1. Preparation of primary amine-guanidines 5.

These primary amine-guanidines $\mathbf{5}$ were used as organocatalysts in the enantioselective Michael addition reaction of aldehydes to $\mathrm{N}$-substituted maleimides. Firstly, the search for the optimal reaction conditions was tackled, and the reaction of isobutyraldehyde (6a) to $N$-phenylmaleimide (7a) was chosen as a model reaction (Table 1). Thus, the reaction between these two compounds organocatalyzed by primary amine-guanidine 5a (20 mol-\%) carried out in toluene as solvent at room temperature afforded the succinimide $(R)-8 \mathbf{8 a}$ in $51 \%$ yield and $76 \%$ ee (determined by chiral HPLC, see the Experimental Section) (Table 1 , entry 1$)$. The $(R)$-stereochemistry for this compound was assigned by comparison of the elution order of the corresponding enantiomers in chiral HPLC with those of the literature. ${ }^{[8 b]}$ The same reaction conditions were employed using primary amine-guanidine $\mathbf{5 b}$ as catalyst, resulting in a higher isolated yield for $(R)$-8aa, although only in a $48 \%$ ee (Table 1, entry 2). Therefore, the optimization study was continued using 5a as organocatalyst.

Other solvents, such as acetone, tert-butyl methyl ether (TBME), nitromethane or methanol were attempted, but the observed enantioselection for $(R)$-8aa resulted much lower than when using toluene (Table 1, entries 3-6). However, the use of DMF as solvent rose the enantioselectivity for $(R)-8 \mathbf{a a}$ up to $82 \%$, although in moderate yield (Table 1, entry 7 ), whereas the use of water as solvent increased the isolated yield and reaction rate, while decreasing slightly the enantioselection (Table 1 , entry 8). Therefore, we assayed combinations on DMF/water as reaction solvent (Table 1, entries 9-11), obtaining quantitative yields of $(R)$-8aa and a highest enantioselectivity of $88 \%$ using a 2/1 mixture of DMF/water (v/v) (Table 1, entry 10).

Once the most appropriate reaction solvent was found $(\mathrm{DMF} /$ water $2 / 1, \mathrm{v} / \mathrm{v})$, we lowered the reaction temperature down to $15^{\circ} \mathrm{C}$ expecting to increase the enantioselectivity. However, the enantiomeric excess remained essentially unchanged and the reaction rate diminished considerably (Table 1 , entry 12). Lowering even more the reaction temperature practically stopped the reaction. In addition, lowering the catalyst loading to $10 \mathrm{~mol}-\%$ also diminished the reaction rate and slightly the enantioselectivity for $(R)-\mathbf{8 a a}$ (Table 1, entry 13 ).

Table 1. Screening and optimization of the reaction conditions for the enantioselective Michael addition.

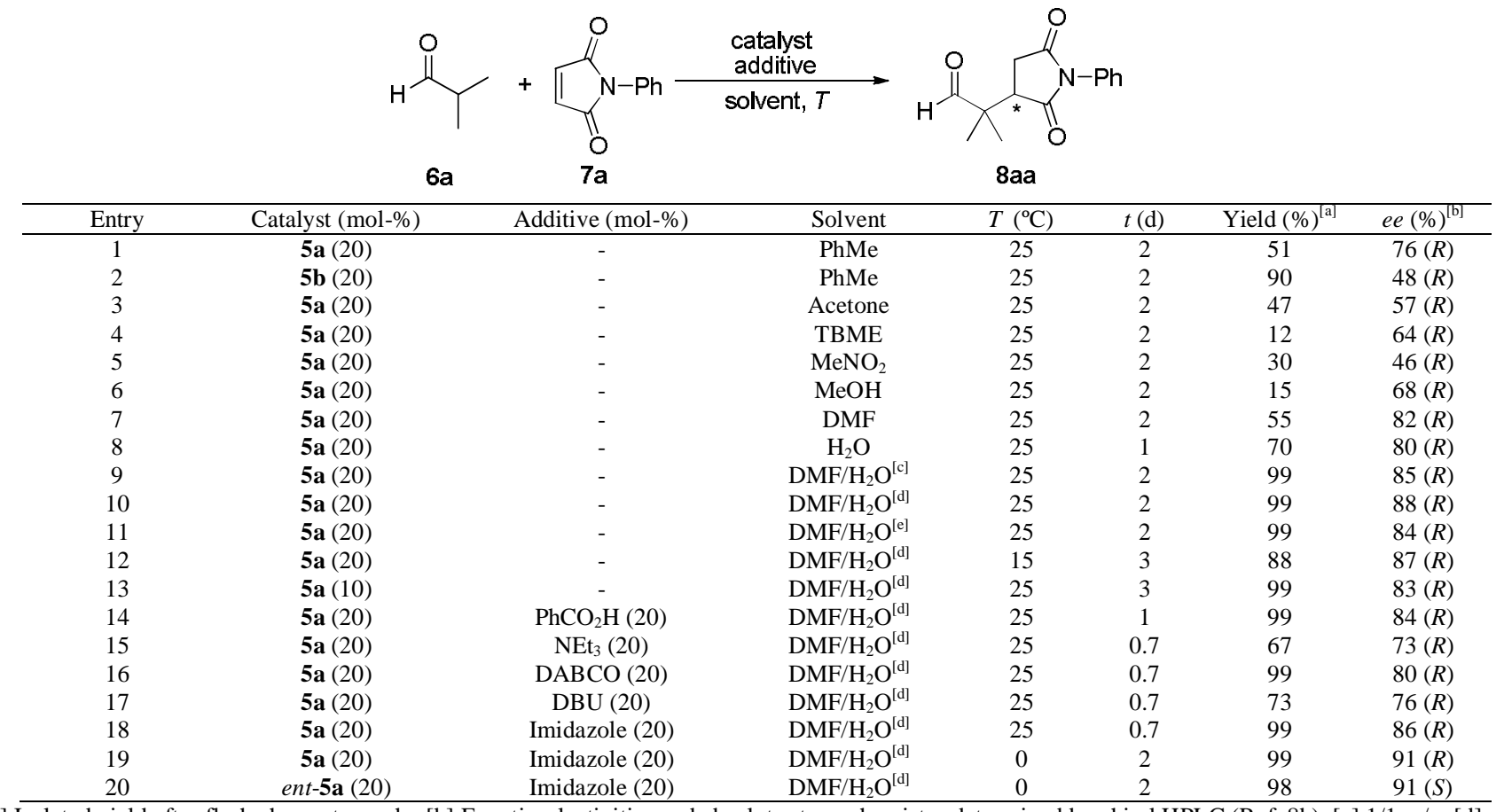

[a] Isolated yield after flash chromatography.[b] Enantioselectivities and absolute stereochemistry determined by chiral HPLC (Ref. 8b). [c] 1/1, v/v. [d] 2/1, v/v. [e] 4/1, v/v.

Subsequently, we explored the possible effect of the presence of some additives. Thus, the addition of benzoic acid (20 mol-\%) to the reaction reduced slightly the enantioselection for $(R)$-8aa although increased the reaction rate (Table 1, entry $14)$. We also attempted basic compounds as additives, considering reported observations that their presence accelerate 
catalytic cycles when enamine-forming organocatalysts are involved. ${ }^{[12]}$ Thus the addition of triethylamine (20 mol-\%) diminished considerably the reaction time, although affording a lower enantioselection for $(R)$-8aa (Table 1, entry 15). In addition, the addition of a 20 mol- $\%$ of other organic bases such as 1,4-diazabicyclo[2.2.2] octane (DABCO) or 1,8diazabicyclo[5.4.0]-undec-7-ene (DBU) also increased the reaction rate, but still giving a lower $e e$ for $(R)-8 \mathbf{a a}$ than when no additive was added (Table 1, entries 16 and 17).

However, the addition to the reaction mixture of a 20 mol- $\%$ of imidazole not only increased the reaction rate and gave a quantitative yield of $(R)$-8aa, but also afforded a $86 \% e e$, a similar value than when no basic additive was present (Table 1 , entry 18). Under these last conditions, the reaction temperature was lowered down to $0{ }^{\circ} \mathrm{C}$, allowing the isolation of succinimide $(R)-8 \mathbf{a a}$ in quantitative yield and in $91 \%$ ee (Table 1, entry 19). Thus, the addition of imidazole as additive allowed lowering down the reaction temperature and increasing the enantioselectivity of the process compared to when no additive was added. ${ }^{[11]}$

Expecting to achieve an opposite enantioinduction, we prepared primary amine-guanidine ent-5a in $51 \%$ yield following the same procedure than in the case of its enantiomeric counterpart 5a, but starting from $(1 R, 2 R)$ cyclohexane-1,2-diamine. This primary amine-guanidine was employed as organocatalyst for the model reaction between isobutyraldehyde and $N$-phenylmaleimide, under the last mentioned reaction conditions, yielding the enantiomeric succinimide (S)-8aa in 98 yield and $91 \%$ ee (Table 1, entry 20 ).<smiles>CCCNC(=[NH2+])N[C@H]1CCCC[C@H]1N</smiles>

Once the best reaction conditions were established [5a (20 mol-\%), imidazole (20 mol-\%), DMF/water $\left.(2 / 1, \mathrm{v} / \mathrm{v}), 0{ }^{\circ} \mathrm{C}\right]$, we proceeded to extend the application of this organocatalytic methodology to other aldehydes and maleimides (Table 2). Thus, when isobutyraldehyde reacted with $\mathrm{N}$-phenylmaleimides bearing halogens on the phenyl ring, such as a chloro atom at the 3- and 4-position (7b and 7c) or a bromo atom at the 4-position (7d), the enantioselectivity for the quantitatively obtained succinimides $(R)$-8ab, $(R)$-8ac and $(R)$-8ad rose up to 95, 92 and $96 \%$, respectively (Table 2, entries 2-4). However, when an electron-releasing methoxy group was present onto the phenyl ring of the maleimide, as in the case of $\mathbf{7 e}$, the enantioselectivity for the corresponding succinimide $(R)$-8ae resulted lowered to $89 \%$ (Table 2, entry 5 ). In addition, the presence of a 4-acetoxy group, as in maleimide $\mathbf{7 f}$, gave rise to the succinimide $(R)$-8af in $94 \%$ ee (Table 2, entry 6).

Table 2. Michael addition of aldehydes to maleimides organocatalyzed by chiral primary amine-guanidine $\mathbf{5 a}$.<smiles>[R]C([R])C(=O)C([R])[R17]</smiles>

\begin{tabular}{|c|c|c|c|c|c|c|c|c|c|}
\hline \multirow[t]{2}{*}{ Entry } & \multicolumn{3}{|c|}{ Aldehyde } & \multicolumn{2}{|c|}{ Maleimide } & \multirow[t]{2}{*}{$t(\mathrm{~d})$} & \multirow[t]{2}{*}{ Succinimide } & \multirow[t]{2}{*}{ Yield $(\%)^{[a]}$} & \multirow[t]{2}{*}{$e e(\%)^{[\mathrm{b}, \mathrm{c}]}$} \\
\hline & $\mathrm{R}^{\mathrm{I}}$ & $\mathrm{R}^{2}$ & No. & $\mathrm{R}^{3}$ & No. & & & & \\
\hline 1 & $\mathrm{Me}$ & $\mathrm{Me}$ & $\mathbf{6 a}$ & $\mathrm{Ph}$ & $7 a$ & 2 & $(R)-8 \mathbf{a a}$ & 99 & 91 \\
\hline 2 & $\mathrm{Me}$ & $\mathrm{Me}$ & $\mathbf{6 a}$ & $3-\mathrm{ClC}_{6} \mathrm{H}_{4}$ & $7 b$ & 3 & $(R)-\mathbf{8} \mathbf{a b}$ & 99 & 95 \\
\hline 3 & $\mathrm{Me}$ & $\mathrm{Me}$ & $6 a$ & 4- $\mathrm{ClC}_{6} \mathrm{H}_{4}$ & $7 \mathrm{c}$ & 3 & $(R)-8 \mathbf{a c}$ & 99 & 92 \\
\hline 4 & $\mathrm{Me}$ & $\mathrm{Me}$ & $6 \mathbf{a}$ & 4- $\mathrm{BrC}_{6} \mathrm{H}_{4}$ & $7 d$ & 2 & $(R)-8 \mathbf{a d}$ & 97 & 96 \\
\hline 5 & $\mathrm{Me}$ & $\mathrm{Me}$ & $\mathbf{6 a}$ & $2-\mathrm{MeOC}_{6} \mathrm{H}_{4}$ & $7 e$ & 2 & $(R)-\mathbf{8 a e}$ & 95 & 89 \\
\hline 6 & $\mathrm{Me}$ & $\mathrm{Me}$ & $\mathbf{6 a}$ & 4- $\mathrm{AcOC}_{6} \mathrm{H}_{4}$ & $7 f$ & 2 & $(R)$-8af & 98 & 94 \\
\hline 7 & $\mathrm{Me}$ & $\mathrm{Me}$ & $\mathbf{6 a}$ & $\mathrm{Bn}$ & $7 \mathrm{~g}$ & 2 & $(R)-8 \mathbf{a g}$ & 99 & 87 \\
\hline 8 & $\mathrm{Me}$ & $\mathrm{Me}$ & $\mathbf{6 a}$ & $\mathrm{Me}$ & $7 \mathrm{~h}$ & 2 & $(R)-8 \mathbf{a h}$ & 99 & 89 \\
\hline 9 & $\mathrm{Me}$ & $\mathrm{Me}$ & $\mathbf{6 a}$ & $\mathrm{H}$ & $7 \mathbf{i}$ & 1 & $(R)-\mathbf{8} \mathbf{a i}$ & 99 & 84 \\
\hline 10 & Et & Et & $\mathbf{6 b}$ & $\mathrm{Ph}$ & $7 \mathbf{a}$ & 4 & $(R)-\mathbf{8 b a}$ & 85 & 95 \\
\hline 11 & \multicolumn{2}{|c|}{$-\left(\mathrm{CH}_{2}\right)_{4^{-}}$} & $6 c$ & $\mathrm{Ph}$ & $7 a$ & 4 & $(R)-8 \mathbf{c a}$ & 92 & 93 \\
\hline 12 & \multicolumn{2}{|c|}{$-\left(\mathrm{CH}_{2}\right)_{5^{-}}$} & 6d & $\mathrm{Ph}$ & $7 \mathbf{a}$ & 4 & $(R)-8 \mathbf{d a}$ & 90 & 93 \\
\hline 13 & $\mathrm{H}$ & $\mathrm{Me}$ & $6 e$ & $\mathrm{Ph}$ & $7 \mathbf{a}$ & 1 & $(S, R) /(R, R)-\mathbf{8 e a}$ & $99^{[\mathrm{d}]}$ & $87 / 87$ \\
\hline 14 & $\mathrm{H}$ & $\mathrm{Bn}$ & 6f & $\mathrm{Ph}$ & $7 \mathbf{a}$ & 1 & $(S, R) /(R, R)-\mathbf{8 f a}$ & $99^{[\mathrm{e}]}$ & $79 / 74$ \\
\hline
\end{tabular}

[a] Isolated yield after flash chromatography. [b] Enantioselectivities determined by chiral HPLC. [c] Absolute configuration determined by the order of elution of the enantiomers in chiral HPLC (see Experimental Section and Supporting Information). [d] Mixture of diastereomers 1.2/1, determined by ${ }^{1} \mathrm{H}$ NMR $(300 \mathrm{MHz})$ in the reaction crude. [e] Mixture of diastereomers 1.9/1, determined by ${ }^{1} \mathrm{H}$ NMR $(300 \mathrm{MHz})$ in the reaction crude. 
Non- $N$-arylated maleimides were also used for the conjugated addition with isobutyraldehyde. Thus, $N$-benzylmaleimide (7g) afforded quantitatively the corresponding succinimide $(R)$-8ag in $87 \%$ ee, whereas $N$-methylmaleimide (7h) gave Michael adduct $(R)$-8ah also quantitatively in $89 \%$ ee (Table 2, entries 7 and 8). Furthermore, the simple maleimide (7i) yielded the succinimide $(R)$-8ai with an enantioselectivity of $84 \%$ and in quantitative yield (Table 2, entry 9). However, an oxygenated analogue such as maleic anhydride gave no reaction.

Other $\alpha, \alpha$-disubstituted aldehydes were employed as pronucleophiles for the organocatalyzed Michael addition reaction to $\mathrm{N}$-phenylmaleimide. Thus, 2-ethylbutanal (6b) gave rise to succinimide $(R)-\mathbf{8 b a}$ in $95 \%$ ee, whereas cyclopentane- $(\mathbf{6 c})$ and cyclohexanecarbaldehyde (6d) gave the corresponding succinimides $(R)$-8ca and $(R)$-8da both in $93 \%$ ee (Table 2, entries 11 and 12). Moreover, the use of $\alpha$-monosubstituted aldehydes such as propanal (6e) and 3-phenylpropanal (6f) afforded quantitatively the Michael adducts $(S, R) /(R, R)$-8ea and $(S, R) /(R, R)$ 8fa, respectively, as mixtures of diastereomers with enantioselections up to 87 and $79 \%$, respectively, for the major isomer [Table 2, entries 13 and 14, see footnotes d) and e)].

The absolute configuration of the known succinimides was assigned according to the elution order of their enantiomers in chiral HPLC when compared to the literature (see Supporting Information), whereas the configuration of the new succinimides was assigned by analogy. In addition, aldehyde $(R)$-8ad resulted converted into the acid $(R)$-9ad upon standing in open air for several days. Crystallization of this compound in $n$-hexane/AcOEt afforded crystals which were used for X-ray analysis (Figure 1). The assigned $(R)$-stereochemistry was confirmed according to the Sheldrick least-squares refinement of the structure, which gave a Flack parameter of $x=0000(13)$.

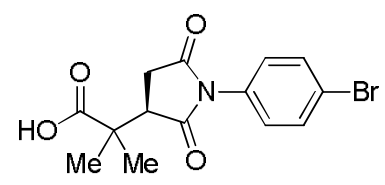

(R)-9ad

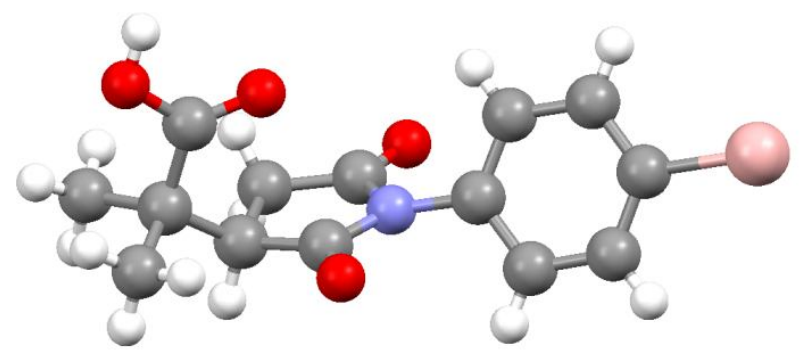

Figure 1. X-Ray structure of compound $(R)-9$ ad.

As an example of the synthetic usefulness of the obtained succinimides $\mathbf{8}$, their transformation to $\gamma$-lactams was carried out following a one-pot tandem reductive amination/lactamization sequence. ${ }^{[3]}$ Thus, enantioenriched crude succinimide $(R)$-8aa ( $91 \%$ ee), obtained by evaporation of the solvent after the Michael addition reaction of isobutyraldehyde and $N$-phenylmaleimide (Table 2, entry 1), was dissolved in chloroform and treated with benzylamine and sodium triacetoxyborohydride. Subsequent spontaneous cyclization afforded lactam $(R)$-10aa in essentially the same enantioselectivity than the starting succinimide $(90 \%$ ee $)$ (Scheme 2).

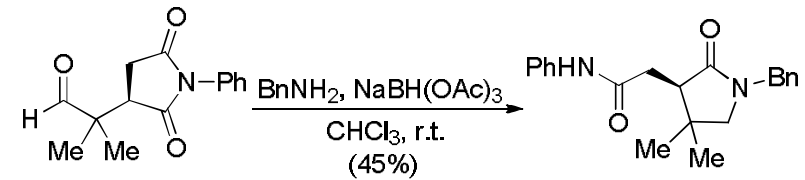

$(R)-8 \mathbf{a a}(91 \%$ ee $)$

(R)-10aa $(90 \%$ ee $)$

Scheme 2. Synthesis of $\gamma$-lactam $(R)$-10aa from enantioenriched succinimide $(R)-\mathbf{8 a a}$ by a tandem reductive amination/lactamization sequence.

The sense of the enantioinduction achieved in this organocatalyzed reaction by using the primary amine-guanidines $\mathbf{5}$ resulted rather unexpected. Thus, the observed $(R)$-stereochemistry in all the formed succinimides $\mathbf{8}$, which is achieved employing organocatalyst 5a derived from $(1 S, 2 S)$-cyclohexane-1,2-diamine, is the same than the observed using as organocatalysts primary amine-thiourea 2 , obtained from enantiomeric $(1 R, 2 R)$ cyclohexane-1,2-diamine. ${ }^{[8 b]}$ This would indicate that the reaction takes place through a different transition state, leading to an opposite stereoinduction.

In order to get further insight into the origin of the observed enantioselectivity achieved by these primary amine-guanidines, and the intriguing enantioselectivity switch between thioureas and guanidines, we carried out theoretical calculations ${ }^{[13]}$ to detail the $\mathrm{H}$-bond activation patterns during the crucial $\mathrm{C}-\mathrm{C}$ bond forming transition state. Structure optimizations were performed at B3LYP/6-311+G** level and single point energies were obtained at M06-2X/6-311+G** level, taking into account in both cases the solvent (water, IEFPCM) effects. We checked the reaction between substrates $6 \mathbf{a}$ and $7 \mathbf{a}$ in the presence of two catalysts, thiourea $\mathbf{2}$ and guanidine 5a. We assumed that the reaction is initiated by the formation of a reactive enamine intermediate between the free $\mathrm{NH}_{2}$ group of the catalyst and the aldehyde. The hydrogen-bonding interaction should then occur between maleimide and the $\mathrm{NH}$ functions (one or two $\mathrm{NH}$ ) of thiourea and/or guanidine moieties. The first computational results showed that, as expected, the thiourea activates the maleimide substrate in a transition state leading preferentially to the $R$ enantiomer [ $8.3 \mathrm{kcal} / \mathrm{mol}(R)$ vs 14.9 $\mathrm{kcal} / \mathrm{mol}(S)$, Figure 2]. The formation of two H-bonds in $R$ and only one in $S$ seems partially responsible for this preference. A closer analysis of the structures indicates that in $\mathrm{TS}_{1}-\mathbf{S}$, the thiourea is also slightly distorted to accommodate the H-bond with the maleimide, which might induce the corresponding energy penalty.

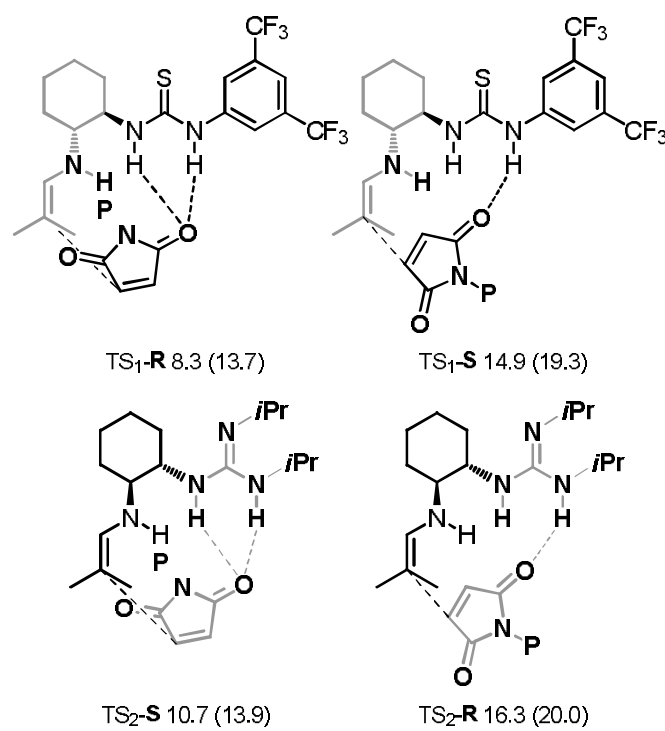

Figure 2. H-bond activation using thiourea 2 and guanidine 5a. Gibbs Free energy (G) values computed at M06-2X/6-311+G** (water) level. Values in parenthesis correspond to the B3LYP method. 
Meanwhile, we found that a similar disposition of the $\mathrm{NH}$ groups in the guanidine would lead to a similar enantiomeric preference (Figure 2), and the transition state $\mathrm{TS}_{2}-\mathbf{S}(10.7 \mathrm{kcal} / \mathrm{mol})$ appeared highly favoured over $\mathrm{TS}_{2}-\mathbf{R}$ structure $(16.3 \mathrm{kcal} / \mathrm{mol})$. Attention must be drawn at this point to the fact that $\mathbf{2}$ and $\mathbf{5 a}$ belong to the opposite enantiomeric series (Figure 2), and thus the computational preference for $R$ in thiourea 2 is equivalent to the preference for $S$ in guanidine 5a. This is in obvious contradiction with the experimental results, which show a large enantiomeric excess in favour of the $R$ form with both catalysts. We assumed that a different activation pattern was necessary to explain these experimental facts. In this regard, we found that the two main conformations of a model cyclohexyl-guanidine (structures G-1 and G-2, Figure 3) do not actually present their NH groups in the parallel disposition necessary for the double H-bond activation (which is the case in $\mathrm{TS}_{2}$ transition states), but instead, the two $\mathrm{NH}$ groups are pointing toward opposite directions. In sharp contrast, the model cyclohexyl-thiourea presents two main conformations of similar energy (T-1 and T-2), and one of them displays the necessary $\mathrm{NH}$ disposition to reach $\mathrm{TS}_{1}$-type structures. ${ }^{[14]}$
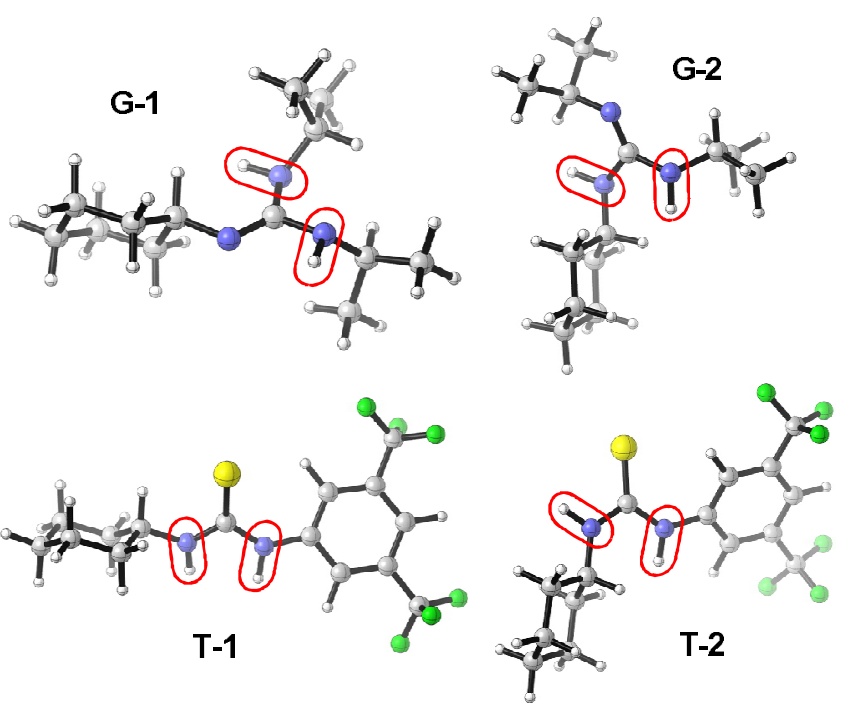

Figure 3.Most stable conformations of cyclohexyl-guanidines (G-1 and G2) and -thioureas (T-1 and T-2).

As a result, $\mathrm{TS}_{2}$ structures were not probably responsible for the activation exerted by guanidines. Indeed, after an important conformational search effort, a pair of structures $\left(\mathrm{TS}_{3}-\mathbf{R}\right.$ and $\mathbf{S}$, Figure 4) were located where the activation of the maleimide is achieved by a single $\mathrm{NH}$ bond pointing to the reaction centre, whereas the other $\mathrm{NH}$ points to the external face of the catalyst (like in G-1, Figure 3). One such transition state $\left(\mathrm{TS}_{3}-\mathbf{R}\right)$ shows the overall lowest activation energy found with $\mathbf{5 a}$, and in agreement with the experimental results, it predicts the right $R$-enantiomer. Examination of the energies of the different transition states in Figures 2 and 4 leads to the conclusion that $R$ enantiomer arises from $\mathrm{TS}_{3}-\mathbf{R}(8.9 \mathrm{kcal} / \mathrm{mol})$, whereas $S$ enantiomer arises from $\mathrm{TS}_{2^{-}}$ $\mathbf{S}(10.7 \mathrm{kcal} / \mathrm{mol})$. These data were obtained using the M06-2X method, which correctly predicts the experimental results. Although B3LYP shows a similar overall trend, it affords less conclusive data, as it shows closer energies for both enantiomers (14.1 kcal/mol in $\mathrm{TS}_{3}-\mathbf{R}$, and $13.9 \mathrm{kcal} / \mathrm{mol}$ in $\left.\mathrm{TS}_{2}-\mathbf{S}\right)$.

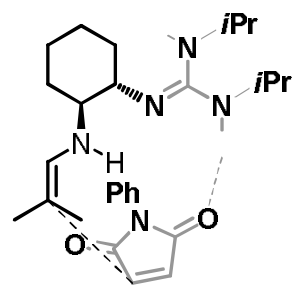

$\mathrm{TS}_{3}-\mathrm{S} 11.4(14.8)$

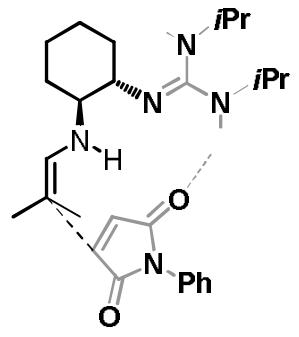

$\mathrm{TS}_{3}-\mathbf{R} 8.9$ (14.1)
Figure 4. H-bond activation using primary amine-guanidine 5a (G-1 type conformation). Gibbs Free Energy (G) values computed at M06-2X/6$311+\mathrm{G}^{* *}$ (water) level. Values in parenthesis correspond to the B3LYP method.

\section{Conclusions}

We conclude that primary amine-guanidines, prepared by a simple monoguanylation of enantiomerically pure trans-cyclohexane-1,2diamines behave as organocatalysts in the enantioselective conjugate addition of aldehydes, including $\alpha, \alpha$-disubstituted, to different maleimides leading to enantiomerically enriched succinimides. High yields and enantioselectivities can be achieved working in aqueous solvents and in the presence of imidazole as rate-accelerating additive. The obtained sense of enantioselectivity results opposite to that reported when primary amine-thioureas are employed as organocatalysts. Theoretical calculations suggest a different hydrogen bond-based coordination pattern between the organocatalyst and the maleimide in the case of these primary amine-guanidines and amine-thioureas. This produces a more favorable transition state when the maleimide is oriented opposite to when an amine-thiourea is involved, thus leading to an opposite enantioselection after internal attack of the formed enamine.

\section{Experimental Section}

General Methods: All the reagents and solvents employed were of the best grade available and were used without further purification. Melting points are uncorrected. Specific rotations were measured using a Perkin-Elmer 341 polarimeter. IR data were collected on a Nicolet Impact 400D-FT spectrometer. The ${ }^{1} \mathrm{H}$ and ${ }^{13} \mathrm{C}$ NMR spectra were recorded at $25{ }^{\circ} \mathrm{C}$ on a Bruker AC-300 at $300 \mathrm{MHz}$ and $75 \mathrm{MHz}$, respectively, using TMS as internal standard. MS (EI, $70 \mathrm{eV}$ ) were performed on an Agilent MS 5973 (DIP) and a HP MS-GC 5973A equipment. HRMS analyses were carried out on a Finnigan MAT 95S. Absolute configuration for adducts 8 was determined according to the described order of elution of their enantiomers in chiral HPLC. The absolute configuration of the new adducts $8 \mathbf{a f}$ and 8ai was assigned by analogy. Reference racemic samples of adducts $\mathbf{8}$ were obtained by performing the reaction using 4-methylbenzylamine (20 mol$\%$ ) as organocatalyst in toluene as solvent at $25^{\circ} \mathrm{C}$. CCDC-930978 [for $(R)$ 9ad] contains the supplementary crystallographic data for this paper. These data can be obtained free of charge at www.ccdc.cam.ac.uk/conts/retrieving.html [or from the Cambridge Crystallographic Data Centre, 12 Union Road, Cambridge CB2 1EZ, UK; fax: (internat.) + 44-1223/336-033; Email: deposit@ ccdc.cam.ac.uk].

Preparation of the Primary Amine-Guanidines: To a solution of $(1 S, 2 S)$ cyclohexane-1,2-diamine (for $\mathbf{5 a}, \mathbf{b})$ or $(1 R, 2 R)$-cyclohexane-1,2-diamine (for ent-5a) $(50 \mathrm{mmol}, 5.71 \mathrm{~g})$ in THF $(10 \mathrm{~mL})$ was added diisopropylcarbodiimide (for $\mathbf{5 a}$ and ent-5a) or dicyclohexylcarbodiimide (for $\mathbf{5 b}$ ) $(10 \mathrm{mmol})$ and the mixture was stirred at $\mathrm{rt}$ for $2 \mathrm{~d}$. The solvent was evaporated (15 torr) and $\mathrm{CH}_{2} \mathrm{Cl}_{2}$ was added $(20 \mathrm{~mL}$ ). The solution was extracted with $2 \mathrm{M} \mathrm{HCl}(3 \times 10 \mathrm{~mL})$ and the aqueous phase was basified with 
$2 \mathrm{M} \mathrm{NaOH}$ until $\mathrm{pH} \approx 9$. Water was evaporated in vacuo (15 torr) and $\mathrm{MeOH}$ was added $(50 \mathrm{~mL})$. The solution was dried $\left(\mathrm{MgSO}_{4}\right)$, filtered and evaporated in vacuo (15 torr) and the crude was purified by column chromatography $\left(\mathrm{CH}_{2} \mathrm{Cl}_{2} / \mathrm{MeOH} 8 / 2\right.$, v/v) affording 5a $(1.20 \mathrm{~g}, 50 \%)$, 5b $(1.60 \mathrm{~g}, 50 \%)$ or ent-5a $(1.22 \mathrm{~g}, 51 \%)$.

Physical and spectroscopic data for compounds $\mathbf{5 a}$ and $\mathbf{5 b}$ are given below:

1-((1S,2S)-2-Aminocyclohexyl)-2,3-diisopropylguanidine (5a): Yellow solid; $\mathrm{mp}=165{ }^{\circ} \mathrm{C}\left(\mathrm{MeOH} / \mathrm{Et}_{2} \mathrm{O}\right) ;[\alpha]^{20}{ }_{\mathrm{D}}=-46.7$ ( $c$ 1, MeOH); IR (ATR): $v=3252,3193,2973,2934,2865,1607,1389,1370,1167,1132,733 \mathrm{~cm}^{-1}$; ${ }^{1} \mathrm{H}$ NMR $\left(300 \mathrm{MHz}, \mathrm{CD}_{3} \mathrm{OD}\right): \delta_{H}=3.99(\mathrm{~m}, 4 \mathrm{H}), 1.94(\mathrm{~m}, 1 \mathrm{H}), 1.76(\mathrm{~m}$, $3 \mathrm{H}), 1.46(\mathrm{~m}, 2 \mathrm{H}), 1.34(\mathrm{~m}, 1 \mathrm{H}), 1.29(\mathrm{~d}, J=6.4 \mathrm{~Hz}, 6 \mathrm{H}), 1.28(\mathrm{~d}, J=6.4$ $\mathrm{Hz}, 6 \mathrm{H}) ;{ }^{13} \mathrm{C}$ NMR $\left(75 \mathrm{MHz}, \mathrm{CD}_{3} \mathrm{OD}\right): \delta_{C}=154.2,56.5,45.8,33.7,25.4$, 22.8; MS (EI, $70 \mathrm{ev)}: \mathrm{m} / z(\%)=240\left(\mathrm{M}^{+}, 5\right), 144$ (100); HRMS (EI): $m / z$ calcd for $\mathrm{C}_{13} \mathrm{H}_{28} \mathrm{~N}_{4}$ : 240.2314; found: 240.2308 .

1-((1S,2S)-2-Aminocyclohexyl)-2,3-dicyclohexylguanidine (5b): White solid; $\mathrm{mp}=184^{\circ} \mathrm{C}\left(\mathrm{MeOH} / \mathrm{Et}_{2} \mathrm{O}\right) ;[\alpha]^{20}{ }_{\mathrm{D}}=-39.6(c 1, \mathrm{MeOH}) ; \mathrm{IR}$ (ATR): $v$ $=3242,3182,2927,2855,1608,1366,1343,1146,1097,727 \mathrm{~cm}^{-1} ;{ }^{1} \mathrm{H}$ NMR (300 MHz, CD 30 OD): $\delta_{H}=7.33(\mathrm{~d}, J=9.0 \mathrm{~Hz}, 1 \mathrm{H}), 4.02(\mathrm{~m}, 1 \mathrm{H})$, $3.63(\mathrm{~m}, 2 \mathrm{H}), 3.45(\mathrm{~m}, 1 \mathrm{H}), 1.87-1.08(\mathrm{~m}, 28 \mathrm{H}) ;{ }^{13} \mathrm{C} \mathrm{NMR}(75 \mathrm{MHz}$, $\left.\mathrm{CD}_{3} \mathrm{OD}\right): \delta_{C}=154.2,56.6,52.7,34.6,33.9,33.8,26.7,26.2,26.1,26.0$, 25.4; MS (EI, $70 \mathrm{ev):} \mathrm{m} / z(\%)=320\left(\mathrm{M}^{+}, 2\right), 224$ (100); HRMS (EI): $\mathrm{m} / \mathrm{z}$ calcd for $\mathrm{C}_{19} \mathrm{H}_{36} \mathrm{~N}_{4}$ : 320.2940 ; found: 320.2934 .

Typical Procedure for the Enantioselective Michael Addition Reaction: To a solution of $\mathbf{5}$ or ent $\mathbf{5 a}(0.04 \mathrm{mmol})$, the maleimide $7(0.2 \mathrm{mmol})$ and imidazole $(0.04 \mathrm{mmol})$ in $\mathrm{DMF} / \mathrm{H}_{2} \mathrm{O}(2 / 1, \mathrm{v} / \mathrm{v})(0.5 \mathrm{~mL})$ was added the aldehyde $6(0.4 \mathrm{mmol})$ and the mixture was stirred at $0{ }^{\circ} \mathrm{C}$ until completion of the reaction (TLC). $2 \mathrm{M} \mathrm{HCl}(10 \mathrm{~mL})$ was added and the mixture was extracted with AcOEt $(3 \times 10 \mathrm{~mL})$. The organic phase was washed with water $(2 \times 10 \mathrm{~mL})$, dried $\left(\mathrm{MgSO}_{4}\right)$, filtered and evaporated (15 torr). The resulting crude was purified by flash chromatography ( $n$-hexane/AcOEt) affording adducts 8 .

Succinimides 8aa, ${ }^{[8 \mathrm{~b}]} \mathbf{8 a b},{ }^{[8 \mathrm{f}]} \mathbf{8 a c},{ }^{[8 \mathrm{~b}]} \mathbf{8 a d},{ }^{[8 \mathrm{f}]} \mathbf{8 a e},{ }^{[8 \mathrm{f}]} \mathbf{8 a g},{ }^{[8 \mathrm{~b}]} \mathbf{8 a h},{ }^{[8 \mathrm{~b}]} \mathbf{8 b a},{ }^{[8 \mathrm{a}]}$ $\mathbf{8 c a},{ }^{[8 c]} \mathbf{8 d a},{ }^{[8 c]} \mathbf{8 e a}{ }^{[8 \mathrm{~b}]}$ and $\mathbf{8 f a}{ }^{[3 \mathrm{a}]}$ have already been described and their ${ }^{1} \mathrm{H}$ NMR and ${ }^{13} \mathrm{C}$ NMR data and retention times in chiral HPLC for both enantiomers can be found in the Supporting Information. Full analytical, spectroscopical data and retention times observed in chiral HPLC for the new compounds 8af and 8ai, as well as for the oxidation product $(R)-9 \mathbf{a d}$, are given below:

(R)-4-(3-(2-Methyl-1-oxopropan-2-yl)-2,5-dioxopyrrolidin-1-yl)phenyl acetate (8af): White solid; $\mathrm{mp}=75^{\circ} \mathrm{C}(n$-hexane/AcOEt $) ;[\alpha]^{20}{ }_{\mathrm{D}}=+1.1(\mathrm{c}$ 1, $\mathrm{CHCl}_{3}$ ); IR (ATR): $v=3055,2968,2933,1703,1684,1386,1260,1188$, $1170,838,742 \mathrm{~cm}^{-1} ;{ }^{1} \mathrm{H}$ NMR $\left(300 \mathrm{MHz}, \mathrm{CDCl}_{3}\right): \delta_{H}=9.49(\mathrm{~s}, 1 \mathrm{H}), 8.05$ $(\mathrm{d}, J=8.5 \mathrm{~Hz}, 2 \mathrm{H}), 7.44(\mathrm{~d}, J=8.5 \mathrm{~Hz}, 2 \mathrm{H}), 3.14(\mathrm{dd}, J=9.6,5.6 \mathrm{~Hz}, 1 \mathrm{H})$, $3.00(\mathrm{dd}, J=18.3,9.6 \mathrm{~Hz}, 1 \mathrm{H}), 2.63(\mathrm{dd}, J=12.7,5.6 \mathrm{~Hz}, 1 \mathrm{H}), 2.62(\mathrm{~s}, 3 \mathrm{H})$ $1.38(\mathrm{~s}, 3 \mathrm{H}), 1.30(\mathrm{~s}, 3 \mathrm{H}) ;{ }^{13} \mathrm{C} \mathrm{NMR}\left(75 \mathrm{MHz}, \mathrm{CDCl}_{3}\right): \delta_{C}=202.8,197.3$, 176.6, 174.5, 136.9, 136.0, 129.8, 129.3, 126.7, 48.9, 45.2, 32.2, 26.8, 20.7, 20.1; MS (EI, $70 \mathrm{ev}): m / z(\%)=303\left(\mathrm{M}^{+}, 0.02\right), 259$ (100); HRMS (EI): $\mathrm{m} / \mathrm{z}$ calcd for $\mathrm{C}_{16} \mathrm{H}_{17} \mathrm{NO}_{5}$ : 303.1107; found: 303.1134; HPLC: Chiralpak AS-H, $\lambda=210 \mathrm{~nm}, n$-hexane/2-propanol, 75:25, $1.0 \mathrm{~mL} / \mathrm{min}, \mathrm{t}_{\mathrm{r}}$ (minor) = $50.2 \mathrm{~min}, \mathrm{t}_{\mathrm{r}}($ major $)=67.7 \mathrm{~min}$.

(R)-2-(2,5-Dioxopyrrolidin-3-yl)-2-methylpropanal (8ai): Colorless oil; IR (film): $v=3235,3077,2973,2938,1779,1698,1353,1290,1179,804$, $659 \mathrm{~cm}^{-1} ;{ }^{1} \mathrm{H}$ NMR $\left(300 \mathrm{MHz}, \mathrm{CDCl}_{3}\right): \delta_{H}=9.49(\mathrm{~s}, 1 \mathrm{H}), 8.73$ (br s, $\left.1 \mathrm{H}\right)$, $3.10(\mathrm{dd}, J=9.4,5.8 \mathrm{~Hz}, 1 \mathrm{H}), 2.85(\mathrm{dd}, J=18.4,9.4 \mathrm{~Hz}, 1 \mathrm{H}), 2.51(\mathrm{dd}, J=$ 18.4, $5.8 \mathrm{~Hz}, 1 \mathrm{H}), 1.25$ (s, 3H), 1.23 (s, 3H); ${ }^{13} \mathrm{C} \mathrm{NMR} \mathrm{(75} \mathrm{MHz,} \mathrm{CDCl}_{3}$ ): $\delta_{C}=202.9,178.3,176.2,48.0,46.3,32.8,20.1,19.4 ;$ MS (EI, $\left.70 \mathrm{ev}\right): \mathrm{m} / \mathrm{z}$ $(\%)=169\left(\mathrm{M}^{+}, 0.66\right), 69$ (100); HRMS (EI): $m / z$ calcd for $\mathrm{C}_{8} \mathrm{H}_{11} \mathrm{NO}_{3}$ : 169.0739; found: 169.0738; HPLC: Chiralpak AD-H, $\lambda=210 \mathrm{~nm}, n$ - hexane/2-propanol, 85:15, $1.0 \mathrm{~mL} / \mathrm{min}, \mathrm{t}_{\mathrm{r}}($ major $)=22.5 \mathrm{~min}, \mathrm{t}_{\mathrm{r}}($ minor $)=$ $30.4 \mathrm{~min}$.

(R)-2-(1-(4-Bromophenyl)-2,5-dioxopyrrolidin-3-yl)-2-methylpropanoic acid (9ad): White solid; $\mathrm{mp}=186^{\circ} \mathrm{C}$ ( $n$-hexane/AcOEt). $[\alpha]^{20}{ }_{\mathrm{D}}=+1.6(c 1$, $\mathrm{CHCl}_{3}$ ); IR (ATR): $v=3000$ (br), 2986, 1706, 1675, 1491, 1401, 1181, 781, $723 \mathrm{~cm}^{-1}$; ${ }^{1} \mathrm{H}$ NMR $\left(300 \mathrm{MHz}, \mathrm{CDCl}_{3}\right): \delta_{H}=7.58(\mathrm{~m}, 2 \mathrm{H}), 7.15(\mathrm{~m}, 2 \mathrm{H})$, $3.14(\mathrm{dd}, J=9.5,5.4 \mathrm{~Hz}, 1 \mathrm{H}), 3.05-2.96(\mathrm{dd}, J=18.1,5.4 \mathrm{~Hz}, 1 \mathrm{H}), 2.70$ $(\mathrm{dd}, J=18.1,5.4 \mathrm{~Hz}, 1 \mathrm{H}), 1.54(\mathrm{~s}, 3 \mathrm{H}), 1.39(\mathrm{~s}, 3 \mathrm{H}) ;{ }^{13} \mathrm{C}$ NMR $(75 \mathrm{MHz}$, $\left.\mathrm{CDCl}_{3}\right): \delta_{C}=180.5,176.5,174.5,132.4,130.8,128.1,122.6,47.0,32.6$, 24.3, 23.6; MS (EI, $70 \mathrm{ev}): m / z(\%)=338\left(\mathrm{M}^{+}, 4.62\right), 57$ (100); HRMS (EI): $\mathrm{m} / \mathrm{z}$ calcd for $\mathrm{C}_{14} \mathrm{H}_{14} \mathrm{BrNO}_{4}: 339.0106$; found: 339.0128 .

One-pot Michael addition/Reductive amination/Lactamization: To a mixture of 1a $(0.08 \mathrm{mmol}, 19.2 \mathrm{mg}), \mathrm{N}$-phenylmaleimide $(0.4 \mathrm{mmol}, 69.2$ $\mathrm{mg})$ and imidazole $(0.08 \mathrm{mmol}, 4.8 \mathrm{mg})$ in $\mathrm{DMF} / \mathrm{H}_{2} \mathrm{O}(2 / 1, \mathrm{v} / \mathrm{v})(0.5 \mathrm{~mL})$ was added isobutiraldehyde $(0.8 \mathrm{mmol}, 73 \mu \mathrm{L})$ at $0{ }^{\circ} \mathrm{C}$. The mixture was stirred at $0{ }^{\circ} \mathrm{C}$ for $2 \mathrm{~d}$ and the solvent was evaporated till dryness (15 torr). The reaction crude was dissolved in $\mathrm{CHCl}_{3}(3.5 \mathrm{~mL})$ and a $1 \mathrm{M}$ solution of benzylamine $(0.8 \mathrm{~mL}, 0.8 \mathrm{mmol})$ in $\mathrm{CHCl}_{3}$ was added, and sodium triacetoxyborohydride $(1 \mathrm{mmol}, 211.9 \mathrm{mg}$ ). The mixture was stirred at $\mathrm{rt}$ for $6 \mathrm{~h}$ and the solvent was evaporated in vacuo (15 torr). To the crude was added $2 \mathrm{M} \mathrm{HCl}(5 \mathrm{~mL})$ and the solution was extracted with $\mathrm{CHCl}_{3}(3 \times 2 \mathrm{~mL})$. The organics were dried $\left(\mathrm{MgSO}_{4}\right)$, filtered and evaporated (15 torr). The resulting crude was purified by flash chromatography ( $n$-hexane/AcOEt gradients) affording the $\gamma$-lactam $(R)$-10aa $(60.6 \mathrm{mg}, 45 \%)$. Physical and spectroscopic data for this compound are given below:

(R)-2-(1-Benzyl-4,4-dimethyl-2-oxopyrrolidin-3-yl)- $\boldsymbol{N}$-phenylacetamide (10aa): Yellow oil; $[\alpha]^{20}{ }_{\mathrm{D}}=+1.6\left(c 1, \mathrm{CHCl}_{3}\right)$; IR (film): $v=3316,3262$, 2986, 1675, 1491, 1401, 1181, 781, $723 \mathrm{~cm}^{-1} ;{ }^{1} \mathrm{H}$ NMR (300 MHz, $\mathrm{CDCl}_{3}$ ): $\delta_{H}=7.62(\mathrm{~m}, 2 \mathrm{H}), 7.41-7-18(\mathrm{~m}, 7 \mathrm{H}), 7.12-7.01(\mathrm{~m}, 1 \mathrm{H}), 4.60(\mathrm{~d}, J=14.6$ $\mathrm{Hz}, 1 \mathrm{H}), 4.38$ (d, $J=14.6 \mathrm{~Hz}, 1 \mathrm{H}), 3.09$ (d, $J=9.7 \mathrm{~Hz}, 1 \mathrm{H}), 2.86(\mathrm{~d}, J=9.7$ $\mathrm{Hz}, 1 \mathrm{H}), 2.81-2.63$ (m, 2H), 2.30 (dd, $J=13.4,0.8 \mathrm{~Hz}, 1 \mathrm{H}), 1.15$ (s, 3H), $0.88(\mathrm{~s}, 3 \mathrm{H}) ;{ }^{13} \mathrm{C} \mathrm{NMR}\left(75 \mathrm{MHz}, \mathrm{CDCl}_{3}\right): \delta_{C}=176.4,170.2,138.8,135.7$, $128.8,128.2,127.9,123.6,119.6,58.9,50.0,46.9,37.9,34.6,25.1,21.8$; MS (EI, $70 \mathrm{ev}): \mathrm{m} / \mathrm{z}(\%)=336\left(\mathrm{M}^{+}, 12.79\right), 244(100)$; HRMS (EI): $\mathrm{m} / z$ calcd for $\mathrm{C}_{21} \mathrm{H}_{24} \mathrm{~N}_{2} \mathrm{O}_{2}$ : 336.1838; found: 336.1851; HPLC: Chiralpak AD, $\lambda$ $=210 \mathrm{~nm}, n$-hexane $/ 2$-propanol, $80: 20,1.0 \mathrm{~mL} / \mathrm{min}, \mathrm{t}_{\mathrm{r}}($ major $)=8.6 \mathrm{~min}, \mathrm{t}_{\mathrm{r}}$ $($ minor $)=9.9 \mathrm{~min}$

\section{Acknowledgments}

We thank the financial support from the Spanish Ministerio de Economía y Competitividad (projects CTQ2010-20387, CTQ201021263-C02 and Consolider Ingenio 2010, CSD2007-00006), FEDER, the Generalitat Valenciana (Prometeo/2009/039), the Basque Government (GV grant IT-291-07)and the universities of Alicante and the Basque Country.We also thank SGI/IZO-SGIker UPV/EHU for allocation of computational resources, and Dr. Tatiana Soler from the Research Technical Services of the University of Alicante for carrying out the X-ray analysis.

[1] For a recent review about organocatalytic addition reactions to maleimides see: P. Chauhan, J. Kaur, S. S. Chimni, Chem. Asian J. 2012, 8, 328-346.

[2] a) A. Fredenhagen, S. Y. Tamura, P. T. M. Kenny, H. Komura, Y Naya, K. Nakanishi, K. Nishiyama, M. Sugiura, H. Kita, J. Am. Chem. Soc. 1987, 109, 4409-4411; b) C. Malochet-Grivois, C. Roussakis, N. Robillard, J. F. Biard, D. Riou, C. Debitus, J. F. Verbist, Anti-Cancer Drug Des. 1992, 7, 493-502; c) Y. Ando, E. Fuse, W. D. Figg, Clin. Cancer Res. 2002, 8, 1964-1973; d) C. Freiberg, N. A. Brunner, G. Schiffer, T. Lampe, M. Pohlmann, D. 
Habich, K. Ziegelbauer, J. Biol. Chem. 2004, 279, 26066-26073; e) M. Isaka, N. Rugseree, P. Maithip, P. Kongsaeree, S. Prabpai, Y. Thebtaranonth, Tetrahedron 2005, 61, 5577-5583; f) J. Uddin, K. Ueda, E. R. O. Siwu, M. Kita, D. Uemura, Bioorg. Med. Chem. 2006, 14, 6954-6961.

[3] a) J. Nöth, K. J. Frankowski, B. Neuenswander, J. Aubé, O. Reiser, J. Comb. Chem. 2008, 10, 456-459; b) E. Fenster, D. Hill, O. Reiser, J. Aubé, Beilstein J. Org. Chem. 2012, 8, 1804-1813.

[4] a) P. A. Reddy, B. C. H. Hsiang, T. N. Latifi, M. W. Hill, K. E. Woodward, S. M. Rothman, J. A. Ferrendelli, D. F. Covey, J. Med. Chem. 1996, 39, 1898-1906; b) K. Das Sarma, J. Zhang, Y. Huang, J. G. Davidson, Eur. J. Org. Chem. 2006, 3730-3737.

[5] a) A. Spaltenstein, M. R. Almond, W. J. Bock, D. G. Cleary, E. S. Furfine, R. J. Hazen, W. M. Kazmierski, F. G. Salituro, R. D. Tung, L. L. Wright, Bioorg. Med. Chem. Lett. 2000, 10, 1159-1162; b) W. M. Kazmierski, W. Andrews, E. Furfine, A. Spaltenstein, L. Wright, Bioorg. Med. Chem. Lett. 2004, 14, 5689-5692.

[6] a) D. M. Barnes, J. Ji, M. G. Fickes, M. A. Fitzgerald, S. A. King, H. E. Morton, F. A. Plagge, M. Preskill, S. H. Wagaw, S. J. Wittenberger, J. Zhang, J. Am. Chem. Soc. 2002, 124, 13097-13105; b) K. Tang, J.-T. Zhang, Neurol. Res. 2002, 24, 473-478.

[7] G.-L. Zhao, Y. Xu, H. Sundén, L. Eriksson, M. Sayah, A. Córdova, Chem. Commun. 2007, 734-735.

[8] a) F. Yu, Z. Jin, H. Huang, T. Ye, X. Liang, J. Ye, Org. Biomol. Chem. 2010, 8, 4767-4774; b) J.-F. Bai, L. Peng, L.-1. Wang, L.-X. Wang, X.-Y. Xu, Tetrahedron 2010, 66, 8928-8932; c) F. Xue, L. Liu, S. Zhang, W. Duan, W. Wang, Chem. Eur. J. 2010, 16, 79797982; d) T. Miura, S. Nishida, A. Masuda, N. Tada, A. Itoh, Tetrahedron Lett. 2011, 52, 4158-4160; e) T. Miura, A. Masuda, M. Ina, K. Nakashima, S. Nishida, N. Tada, A. Itoh, Tetrahedron: Asymmetry 2011, 22, 1605-1609; f) Z.-w. Ma, Y.-x. Liu, P.-1. Li, H.
Ren, Y. Zhu, J.-c. Tao, Tetrahedron:Asymmetry 2011, 22, 17401748; g) Z.-W. Ma, Y.-X. Liu, W.-J. Zhang, Y. Tao, Y. Zhu, J.-C. Tao, M.-S. Tang, Eur. J. Org. Chem. 2011, 6747-6754.

[9] T. C. Nugent, A. Sadiq, A. Bibi, T. Heine, L. L. Zeonjuk, N. Vankova, B. S. Bassil, Chem. Eur. J. 2012, 18, 4088-4098.

[10] a) T. Ishikawa, T. Isobe, Chem. Eur. J. 2002, 8, 553-557; b) D. Leow, C.-H. Tan, Chem. Asian. J. 2009, 4, 488-507; c) T. Ishikawa, Chem. Pharm. Bull. 2010, 58, 1555-1564; d) D. Leow, C.-H. Tan, Synlett 2010, 1589-1605; e) X. Fu, C.-H. Tan, Chem. Commun. 2011 , 47, 8210-8222; e) P. Selig, Synthesis 2013, 45, 703-718.

[11] A. Avila, R. Chinchilla, C. Nájera, Tetrahedron: Asymmetry 2012, $23,1625-1627$

[12] X.-j. Zhang, S.-p. Liu, X.-m. Li, M. Yang, A. S. C. Chan, Chem. Commun. 2009, 833-835.

[13] For computational details, see Supporting Information.

[14] The corresponding T-1-like conformation of the model guanidine lies $>3 \mathrm{kcal} / \mathrm{mol}$ higher in energy than the G-1 structure, and is not competitive.

Received: ((will be filled in by the editorial staff)) Published online: ((will be filled in by the editorial staff)) 